\title{
THE TIMING OF INITIAL SPRING MELT IN THE ARCTIC FROM NIMBUS-7 SMMR DATA
}

\section{(Abstract)}

\author{
by
}

Mark R. Anderson

(California Space Institute, A-021. Scripps Institution of Oceanography, La Jolla, CA 92093, U.S.A.)

\begin{abstract}
The ablation of sea ice is an important feature in the global climate system. During the melt season in the Arctic, rapid changes occur in sea-ice surface conditions and areal extent of ice. These changes alter the albedo and vary the energy budgets. Understanding the spatial and temporal variations of melt is critical in the polar regions. This study investigates the spring onset of melt in the seasonal sea-ice zone of the Arctic Basin through the use of a melt signature derived by Anderson and others from the Nimbus-7 Scanning Multichannel Microwave Radiometer (SMMR) data. The signature is recognized in the "gradient ratio" of the 18 and $37 \mathrm{GHz}$ vertical brightness temperatures used to distinguish multi-year ice. A spuriously high fraction of multi-year ice appears rapidly during the initial melt of sea ice, when the snow-pack on the ice surface has started to melt. The brightness-temperature changes are a result of either enlarged snow crystals or incipient puddles forming at the snow/ice interface.

The timing of these melt events varies geographically
\end{abstract}

and with time. Within the Arctic Basin, the melt signatures are observed first in the Chukchi and Kara/Barents Seas. As the melt progresses, the location of the melt signature moves westward from the Chukchi Sea and eastward from the Kara/Barents Seas to the Laptev Sea region. The timing of the melt signal also varies with year. For example, the melt signature occurred first in the Chukchi Sea in 1979, while in 1980 the signature was first observed in the Kara Sea.

There are also differences in the timing of melt for specific geographic locations between years. The melt signature varied almost 25 days in the Chukchi Sea region between 1979 and 1980. The other areas had changes in the 7-10 day range.

The occurrence of these melt signatures can be used as an indicator of climate variability in the seasonal sea-ice zones of the Arctic. The timing of the microwave melt signature has also been examined in relation to melt observed on short-wave imagery. The melt events derived from the SMMR data are also related to the large-scale climate conditions.

\section{MICROWAVE SNOW-WATER EQUIVALENT MAPPING OF THE UPPER COLORADO RIVER BASIN, U.S.A.}

(Abstract)

by

W.J. Campbell and E.G. Josberger

(University of Puget Sound, Tacoma, WA 98416, U.S.A.)

P. Gloersen

(Laboratory for Oceans, NASA Goddard Space Flight Center, Greenbelt, MD 20771, U.S.A.)

and

A.T.C. Chang

(Laboratory for Terrestrial Physics, NASA Goddard Space Flight Center, Greenbelt, MD 20771, U.S.A.)

\begin{abstract}
During spring 1984, a joint agency research effort was made to explore the use of satellite passive microwave techniques to measure snow-water equivalents in the upper Colorado River basin. This study involved the near real-time acquisition of microwave radiances from the Scanning Multichannel Microwave Radiometer (SMMR) aboard the Nimbus-7 satellite, coupled with quasisimultaneous surface measurements of snow-pack depth and profiles of temperature, density, and crystal size within the basin. A key idea in this study was to compare, for the
\end{abstract}

same space and time-scales, the SMMR synoptic physics data taken in the basin. Such a snow-measurement program was logistically difficult, but two field teams took detailed snow-pit measurements at 18 sites in Colorado, Utah, and Wyoming during the last 2 weeks of March, when the snow-pack is normally at its maximum extent and depth. These observations were coupled with snow-water-equivalent measurements from Soil Conservation Service SNOTEL sites. Microwave-gradient ratio, $\mathrm{Gr}$ ( $\mathrm{Gr}$ is the difference of the vertically polarized radiances at $8 \mathrm{~mm}$ and $17 \mathrm{~mm}$ divided 
by the sum), maps of the basin were derived in a near real-time mode every 6 days from SMMR observations. The sequential $\mathrm{Gr}$ maps showed anomalously low values in the Wyoming snow-pack when compared to the other states. This near real-time information then directed the field teams to Wyoming to carry out an extensive survey, which showed that these values were due to the presence of depth hoar; the average crystal sizes were more than twice as large as in the other areas. SMMR can be used to monitor the spatial distribution and temporal evolution of crystal size in snow-packs. Also, scatter diagrams of snow-waterequivalents from the combined snow-pit and SNOTEL observations versus $\mathrm{Gr}$ from the Wyoming part, and the Colorado and Utah part, of the basin can be used to estimate snow-water equivalents for various parts of the basin.

\section{COMPARISON OF LANDSAT MULTISPECTRAL SCANNER AND THEMATIC MAPPER RADIOMETRIC AND SPATIAL CHARACTERISTICS OVER GLACIERS}

\section{(Abstract)}

by

J.A. Dowdeswell*

(Scott Polar Research Institute, University of Cambridge, Cambridge CB2 1ER, U.K.)

\section{ABSTRACT}

For more than 10 years, images obtained from the four Landsat Multispectral Scanner (MSS) bands have provided important data for mapping and glaciological studies in the inaccessible polar regions. During this period, the specifications of the MSS have remained little altered, to allow data comparability. More recently, satellites 4 and 5 of the Landsat series have been equipped additionally with Thematic Mapper (TM) sensors. The TM has 7 bands in the visible, near infra-red, mid infra-red, and thermal infra-red, together with a larger dynamic range and improved spatial resolution relative to the MSS. The aim of this paper is to compare MSS and TM computer-compatible tapes (CCTs) from a glacierized area in order to demonstrate the advantages of using TM data in glaciological applications.

The digital MSS and TM scenes compared were imaged simultaneously from Landsat 5 on 5 May 1984 over the north-west part of Spitsbergen, Svalbard (path 218, row 3). This location was selected because of the range of glaciological features present: numerous valley glaciers, the ice field of Holtedahlfonna, fast ice, and ice floes. Partially cloud-covered imagery was preferred, to allow comparison of the two sensors in terms of their ability to distinguish between clouds and snow. The time of year is also advantageous, in that Sun elevation $\left(27^{\circ}\right)$ is high enough for detector saturation to occur in MSS band 2 (Dowdeswell and McIntyre 1986). Surface-elevation data from airborne radio echo-sounding, and other ancilliary glaciological information, are also available for this part of Svalbard.

Differences in the dynamic range and the wavelengths over which TM and MSS data are collected have two main implications for glaciological studies. First, snow and snow-

* Present address: Department of Geography, University College of Wales, Aberystwyth, Penglais, Aberystwyth, Dyfed SY23 3DC, U.K. covered ice masses can be distinguished easily from cloud cover in TM band $5(1.57$ to $1.78 \mu \mathrm{m})$. Snow appears dark whereas clouds are light at this wavelength. For example, thin clouds over part of Oscar II Land in Spitsbergen became apparent. In many MSS scenes of the Antarctic, the cloud-free ice-sheet surface has been misidentified as cloudcovered during quality-control analysis. Secondly, the wider dynamic range of the TM sensors means that saturation occurs less frequently over snow than was the case with MSS imagery. Digital analysis of MSS and TM scene radiance over Spitsbergen demonstrates this fact and implies that ice-surface topographic information will only rarely be degraded in TM imagery, although TM band $1(0.45$ to $0.52 \mu \mathrm{m})$ is most of ten saturated.

The nominal spatial resolution of TM sensors is $30 \mathrm{~m}$, except for the thermal infra-red band. This is a significant improvement over the $79 \mathrm{~m}$ by $56 \mathrm{~m}$ resolution of the MSS. A major advantage of this is that ice margins and ice-surface features can be more precisely identified. More accurate glacier maps can be made, and smaller variations in termini positions of outlet glaciers can be monitored. Ice-surface features, such as crevasses, are more likely to be recorded on TM imagery, and examples are shown from Spitsbergen glaciers. The identification of such features is of major importance in studies of ice-surface velocities from Landsat imagery. For sea-ice applications, the ability to identify smaller floes is also important; for example, in the analysis of floe-size distributions.

The only significant drawbacks to the use of Landsat TM data in glaciological studies are the expense, particularly in the more useful digital format, and the small amount of coverage yet available for the polar regions.

\section{REFERENCE}

Dowdeswell J A, McIntyre N F 1986 The saturation of Landsat MSS detectors over large ice masses. International Journal of Remote Sensing 7: 151-164 